Pteridines

Vol. 13, 2002,pp. $107-114$

\title{
Folate Supplementation in Rats: Does it Cause Behavioural and Electrophysio- logical Changes?
}

\author{
Terken Baydar', Andras Papp², Laszlo Nagymajtényi', Horst Schulz', Gonul Sahin'
}

'Department of Toxicology, University of Hacettepe, Faculty of Pharmacy, Ankara, Turkey

${ }^{2}$ Department of Public Health, University of Szeged, Faculty of Medicine, Szeged, Hungary

\begin{abstract}
Folate supplementation is becoming increasingly popular not only to decrease homocystein, a long with the finding that moderate hyperhomocysteinaemia is a cardiovascular risk factor but also diminish some other risks related to folate depletion. The aim of the study was to investigate whether folic acid supplementation leads to behavioural and electrophysiological changes in rats. Therefore, 30 male Wistar rats were divided to three groups. Each of animal groups was consisted of 10 animals. Folic acid was applied to rats by gavage for 8 weeks. Group 1 as a control group was taking folic acid-free water by gavage throughout the duration of the experiment. Groups 11 and III were treated with $2.0 \mathrm{mg} / \mathrm{kg} /$ day and $20.0 \mathrm{mg} / \mathrm{kg} /$ day of folic acid, respectively. Behavioural effects were evaluated by open field motor activity and by acoustic startle response. Electrophysiological examination is done by recording spontaneous activity and sensory evoked potentials from the visual, somatosensory, as well as auditory cortex. No significant effects on motor activity or acoustic startle response were observed. Both doses of folic acid shortened the latency of the visual cortical evoked potential $(\mathrm{p}<0.05)$ and caused a slightly but nonsignificant change in the relative refractory period of a peripheral nerve. There was no effect on the electrocorticograms or on the other evoked potentials. Among the investigated organs, significant differences were observed in relative weight of kidneys and adrenal glands among the folic acid treatment at both the doses and the control groups $(\mathrm{p}<0.05)$.
\end{abstract}

Key words: folic acid, subchronic, rat, behaviour, electrophysiology

\section{Introduction}

The water-soluble vitamin folic acid (folate) is essential for cell replication and all physiological requirements for folic acid usually are met by a normal diet. Folic acid and its reduced derivatives are vital cofactors in one-carbon transformation in the body. Disturbances of these interdependent reactions cause impairment biological pathways such as protein synthesis, synthesis and repair of DNA, etc. It is known that folic acid and its active forms play roles at least in thirteen different and important enzymatic reactions in the body (1-4).

Folic acid has become very popular since the early 1990 s, mainly due to the report that supplementation of the diet with the vitamin during the periconception- al period and in early pregnancy can reduce the incidence of congenital abnormalities, like neural-tube defects (4-6). Additionally, there is now agreement that subnormal folate supply is associated with hyperhomocysteinaemia, recently confirmed as a new risk factor for cardiovascular disease $(7,8)$. The concept of dietary folate equivalents differentiates naturally occurring food folate from synthetic folate (used for dietary supplementation and fortification) because of their different bioavailabilities. The minimum effective and safe dose of folic acid to prevent neural tube defect or reduce high homocysteine levels still remains unknown $(2,5-8)$.

In spite of these links, the specific role(s) that folic acid pathway plays in the central nervous system has/have yet to be shown. Folate in central nervous

Correspondence to: Dr.Gonul Sahin, Hacettepe University, Department of Toxicology,Faculty of Pharmacy, 90-06100 Ankara TURKEY, Tel.: ++90 (312) 30518 51;Fax: ++90 (312) 31147 77; E-mail: gsahin@hacettepe.edu.tr 
system is regulated by several mechanisms. These as well as the molecular identity of folate transport system(s) in the brain and gastrointestinal tract has been a subject of several investigations. The blood-brain barrier contains folate receptors, which are involved in transport of reduced folate derivatives. Possible suggestions for the further development of therapeutic potentials have been based on the understanding of these processes. The usual maintenance of folate concentration also depends on the activity of enzymes catalysing conjugation, methylation, oxidation and other reactions involved in folate-related metabolic pathways (3-5, 9-12).

So far, effects of folate deficiency related to various factors have been well documented rather than those of excessive or uncontrolled consumption of the vitamin. However it is commonly used for this purpose, but only a limited number of studies has been done on the subject. However folic acid generally has been regarded as non-toxic, recently folic acid has been accused of being a potential risk, but its toxicity is controversial. It has been shown that folic acid causes some adverse effects in laboratory animals such as body weight changes, tubular dilatation, renal hypertrophy and diuresis along with some changes in biochemical parameters. In humans, adverse effects of the vitamin are rarely documented. There is no coherence between the reports $(6,13-16)$. Folates precipitate or worsen neurological injury in patients with pernicious anaemia, produce convulsions after systemic or intracranial injections in rodents and other species, and produce excitotoxic brain lesions which share some but not all features of kainic acid neurotoxicity (16). There is very limited and conflicting number of documentations in humans.

Therefore, in order to evaluate effects of excessive amount of folic acid in the present study the doses were chosen 10- and 100- fold of its acceptable daily dose considered as $15 \mathrm{mg}$ per day for healthy adults $(11,13,15)$. It was designed to investigate whether subchronic folic acid at two-level doses causes behavioural and clectrophysiological changes in rats.

\section{Materials and Methods}

\section{Experimental Design}

Thirty Wistar rats (mean body weights: $255.4 \pm 26.12 \mathrm{~g}$ ) were drawn from Research Institute of Laboratory Animals, Gödöllö- Hungary. During the treatment period, the rats were housed in an animal room, 5 each in a cage, at 22 to $24^{\circ} \mathrm{C}$ and $65 \%$ humidity with 12:12 hours light-dark cycle, and all tests took place during the light period. The rats had access to food and water ad libitum. The animals were divided into three groups: Group I $(n=10)$ was treated with distilled water as a control group, while Group II $(n=10)$ and Group III $(\mathrm{n}=10)$ were treated with folic acid at 2.0 $\mathrm{mg} / \mathrm{kg} \mathrm{b.w}$. and $20.0 \mathrm{mg} / \mathrm{kg} \mathrm{b.w.} \mathrm{concentrations,}$ respectively. Treatments were applied by gavage for 8 weeks in a 5 days per week schedule. Changes in body weights of the animals were observed once a week.

\section{Behavioural Tests}

Motility and spontaneous exploration was investigated in an automatic open field (OF: $40 \times 40 \times 40 \mathrm{~cm}$; ACTIFRAME, Gerb Electronic, Berlin-Germany). Activity was recorded in 10 -min sessions after 2 and 8 weeks of exposure before the daily administrations. Horizontal, vertical as well as stationary movements, and speed of movements were detected by infrared sensors (IR). Illumination of the OF floor was $10 \mathrm{~lx}$, and $30 \mathrm{~dB}$ white background noise.

Auditory startle response (ASR) and the 'Pre-PuiseInhibition' were measured in a subsequent regime by use of the Responder X (Columbus Instruments, Ohio, USA) equipment. Stimulation frequency: $5000 \mathrm{~Hz}$ for the eliciting stimulus, $1000 \mathrm{~Hz}$ for the pre-stimulus. Pre-stimulus of $500 \mathrm{~ms}$ duration was applied with 50 dB $200 \mathrm{~ms}$ before the eliciting stimulus (110 dB and $200 \mathrm{~ms}$ duration). Ten stimuli were applied per session in a random sequence with intervals between 10 and 15 $\mathrm{sec}$. As a positive response crossing of the $50 \mathrm{~g}$ threshold was accepted and latency, peak-time, and peak amplitude were measured.

Evaluation of Electrophysiological Test Parameters

After the behavioural investigations, electrophysiological tests were done. Spontaneous and stimulusevoked cortical activity was recorded from the animals in acute preparation. Each animal was anaesthetised with $1000.0 \mathrm{mg} / \mathrm{kg}$, ip urethane and placed in a stereotaxic frame. The left hemisphere was exposed by opening the skull and ball-tipped silver wire electrodes were placed on the primary somatosensory (Parl), visual (Oc1B) and auditory ( $\mathrm{Te} 1)$ cortical areas. Following a recovery of ca. $30 \mathrm{~min}$., simultaneous electrocorticogram (ECoG) was recorded form these points for $5 \mathrm{~min}$. From the same locations, sensory evoked potentials were subsequently recorded. Somatosensory stimulation was done by a pair of needles delivering electric shocks ( $1 \mathrm{~Hz}, 3-4 \mathrm{~V}, 0.2 \mathrm{~ms})$ to the whiskery part of the skin. For visual stimulation flashes $(1 \mathrm{~Hz}, 60 \mathrm{~lx})$ of a flashbulb were directed to the contralateral eye via an optical conductor. Acoustic stimuli (clicks, $1 \mathrm{~Hz}, 40 \mathrm{~dB}$ ) were delivered through the hollow ear bar into the contralateral ear of the rat.

Recording and stimulation of the activities was performed by a system (Neurosys, Experimetria Ltd, UK). 
The $\mathrm{ECoG}$ analysis yielded the mean frequency, mean amplitude, and the frequency band power spectrum. ECoG index, the ratio of the spectral power slow and fast bands (delta+theta/beta1+beta2), was also calculated (17). As to evoked activity, 50 potentials of each modality were averaged, and latency, duration and amplitude of the main waves were measured manually on the screen.

Functioning of the peripheral nervous system was tested on the tail nerve. From the data, relative and absolute refractory period was calculated.

Investigation of Relative Tissue Weights

Just after the electrophysiological recordings, the rats were killed with overdose of urethane. Brain, thymus, spleen, kidney, lung, heart and liver were removed, and weighed for the calculation of relative tissue weights.

The principles of the Ethical Committee for the Protection of Animals in Research of the University were strictly followed during the whole study.

\section{Statistical analysis}

Kolmogorov-Smirnov test was used first to check the normality of the data. Behavioural effects were analysed by multivariate ANOVA following square root transformation of the data by a $3 \times 3$ (time $\mathrm{X}$ doses) design for equal cell content or by non-parametric Kruskal-Wallis ANOVA. The electrophysiological data were analysed by a one-way ANOVA. LSD test was used for a post hoc analysis of group differences. A probability level of $\mathrm{p}<0.05$ was accepted as significant.

\section{Results}

During the treatment period, no visible adverse effect was observed in all groups. There was no significant difference among the changes of their body weight gains during the treatment period $(\mathrm{p}>0.05$, Tab. 1).

Figure 1 and 2 show the open-field and acoustic startle response findings, respectively. Folic acid affected none of the behavioural parameters measured

Table 1: Changes in body weights of the groups during the experiment (there were no significant differences between controls and treatment groups, $\mathrm{p}>0.05$ )

\section{GROUPS}

(body-weights, mean $\pm \mathrm{SD}, \mathrm{g}$ )

\begin{tabular}{cccc}
$\begin{array}{c}\text { Treatment Period } \\
\text { (week) }\end{array}$ & I & II & III \\
\cline { 2 - 4 } & Control & $2.0 \mathrm{mg} / \mathrm{kg}$, folic acid & $20.0 \mathrm{mg} / \mathrm{kg}$, folic acid \\
\hline 0 (pre-treatment) & $263.1 \pm 21.20$ & $249.4 \pm 26.20$ & $253.8 \pm 30.96$ \\
1 & $315.6 \pm 22.50$ & $302.5 \pm 30.00$ & $309.4 \pm 33.56$ \\
2 & $353.8 \pm 28.26$ & $348.8 \pm 37.92$ & $359.4 \pm 38.03$ \\
4 & $384.4 \pm 28.04$ & $381.3 \pm 41.93$ & $375.6 \pm 45.01$ \\
5 & $412.5 \pm 28.17$ & $417.5 \pm 52.34$ & $417.5 \pm 50.13$ \\
6 & $435.6 \pm 35.21$ & $441.3 \pm 54.63$ & $443.1 \pm 53.00$ \\
7 & $461.3 \pm 35.94$ & $466.3 \pm 59.65$ & $470.6 \pm 51.44$ \\
8 & $-30.6 \pm 31.93$ & $490.6 \pm 60.93$ & $503.8 \pm 56.44$ \\
& $-5-5 \pm 39.02$ & $493.8 \pm 66.42$ & $496.9 \pm 61.94$
\end{tabular}



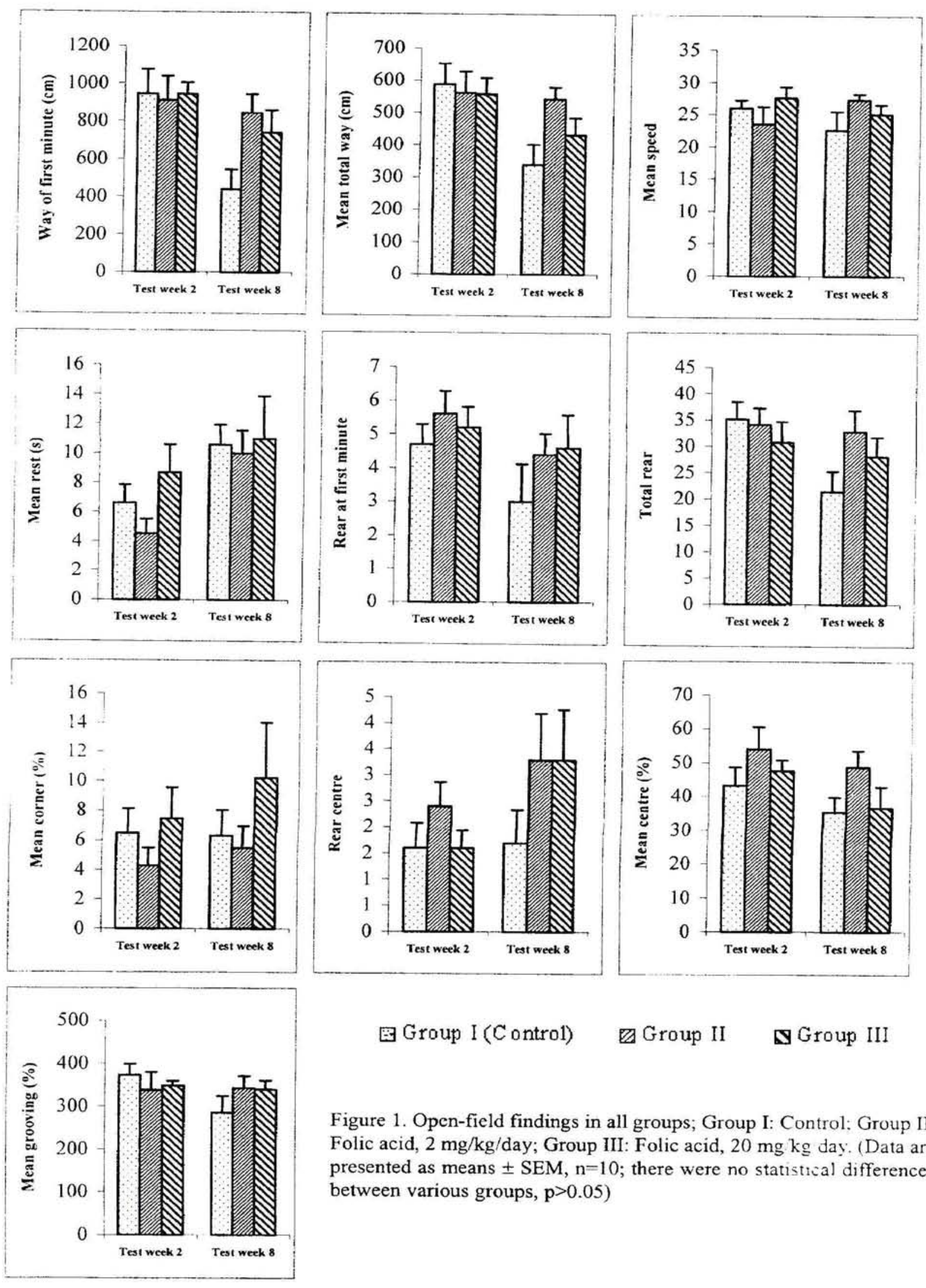

国 Group I (Control) $\approx$ Group II $\$$ Group III

Figure 1. Open-field findings in all groups; Group I: Control: Group II: Folic acid, $2 \mathrm{mg} / \mathrm{kg} /$ day; Group III: Folic acid, $20 \mathrm{mg} \mathrm{kg}$ day. (Data are presented as means $\pm S E M, n=10$; there were no statistical differences between various groups, $\mathrm{p}>0.05$ ) 

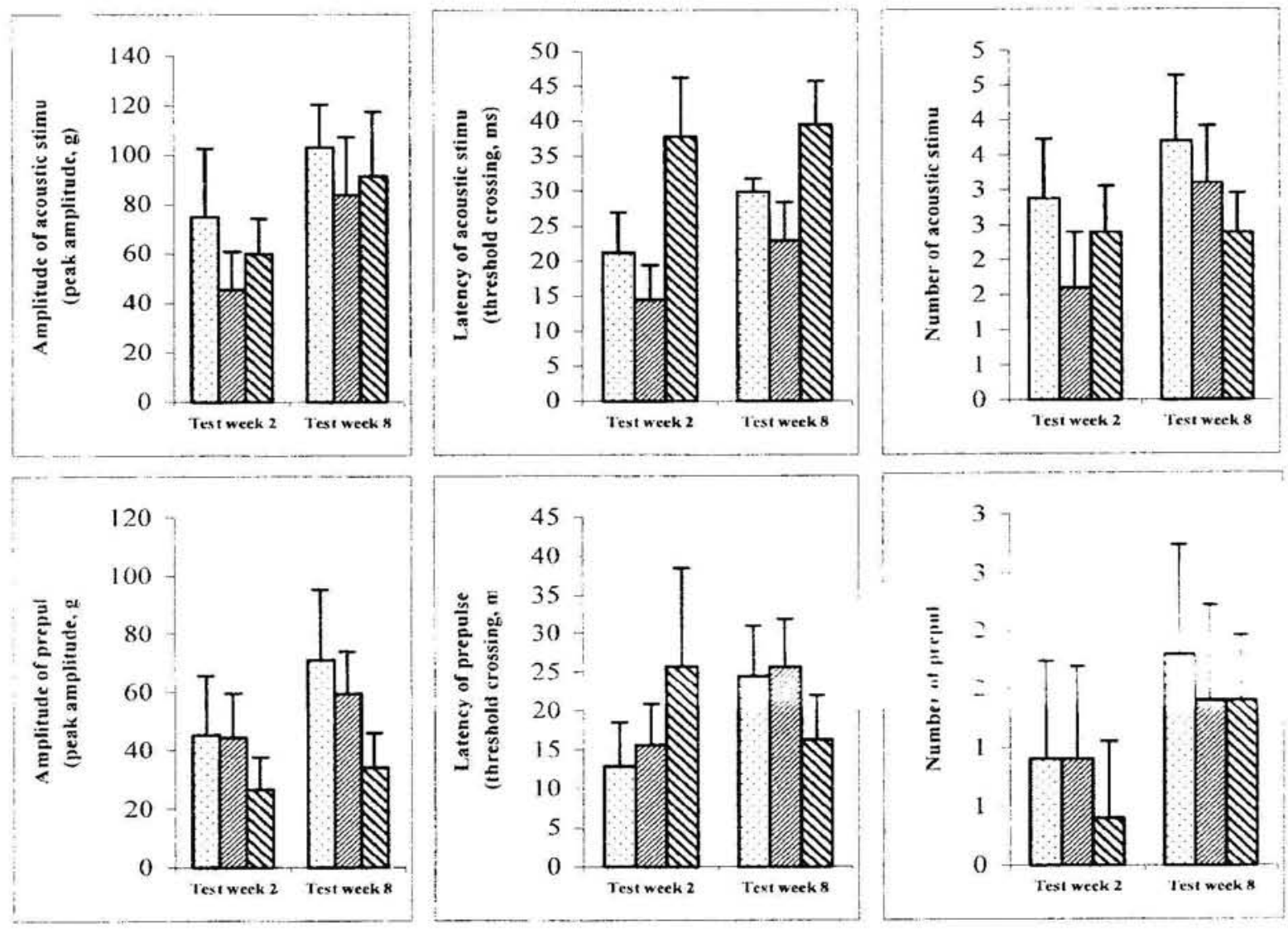

\section{G Group I (Control) $\square$ Group II \$ Group III}

Figure 2. Acoustic startle response findings in all groups; Group I: Control; Group II: Folic acid, $2 \mathrm{mg} / \mathrm{kg} / \mathrm{day}$; Group III: Folic acid, $20 \mathrm{mg} / \mathrm{kg} /$ day. (Data are presented as means $\pm \mathrm{SEM}, \mathrm{n}=10$; there were no statistical differences between various groups, $\mathrm{p}>0.05$ )

at either dose levels. No significant differences were observed in horizontal and vertical behaviour activities and startle responses in treatment week 2 or week 8 $(p>0.05)$. There were also no dose-related differences between the groups $(\mathrm{p}>0.05)$.

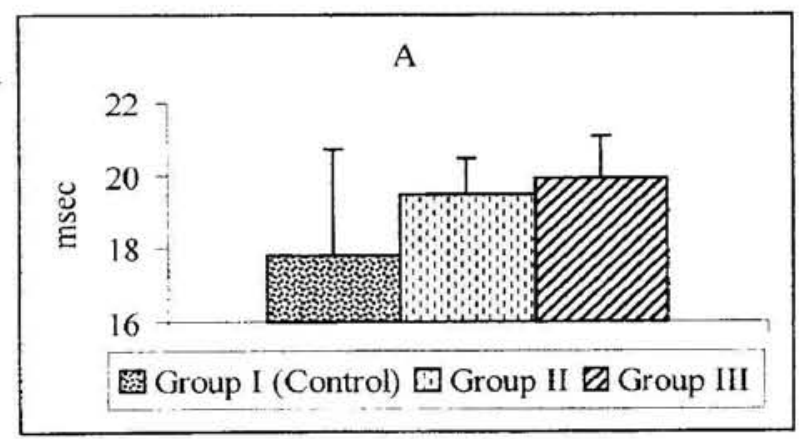

The changes of latency and duration of the evoked potentials were treatment-dependent. In case of the somatosensory evoked potentials the latency of waves increased in the treated groups, Fig. 3A, but there were no significant differences between the groups in

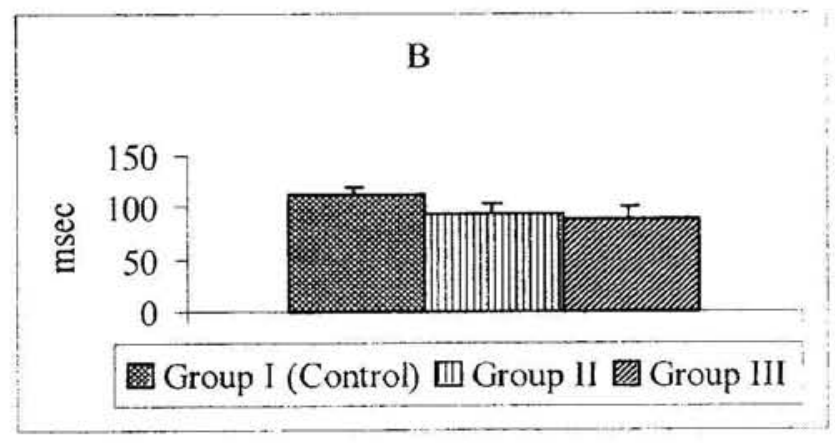

Figure 3: Changes of the latency of certain evoked potential waves (A - somatosensory N2 wave; $p>0.05$; $\mathrm{B}$ - visual N1 wave; $\mathrm{p}<0.001$, group I vs. group II, group I vs group III) 
lengthening of the latency $\mathrm{N} 1$ and N2 waves, $(\mathrm{p}>0.05$, in all cases). The interpeak durations also became longer, but the differences were not significant. In case of the visual evoked potential, the latency of waves decreased dose-dependently in the study. The change of the wave was significant in the treatment and control groups $(F(2,27)=16.58, p<0.001$ Fig. $3 B)$, but the difference between folic acid in treated groups was not significant $(p>0.05)$. Shorter interpeak durations were seen in all treated-groups, but the changes were not significant either $(\mathrm{p}>0.05)$.

There were similar trends of changes of the ECoG power spectra. The slow wave part (delta and theta) was slightly increased and the fast wave part (betal and beta2) was not changed in all treatment groups $(p>0.05)$. Intervariational comparison of identical parameters (amplitude, frequency, index) of ECoGs revealed no significant differences $(\mathrm{p}>0.05)$.

The conduction velocity of the tail nerve was decreased in the treated groups, but the differences between the groups were insignificant $(p>0.05)$. The relative and absolute refractory periods also did not differ in length. No significant intervariation differences of corresponding parameters from different groups were found $(\mathrm{p}>0.05)$.

There was no effect of folic acid treatment on whole brain weights (Tab. 2, p>0.05). To calculate relative

\section{Discussion}

Apart from many crucial functions which folic acid has in the organism, limited number of data has suggested that it has also a subtle role in central nervous system $(5,9,11)$. It is unclear that for how long and at what dosage folate should be supplemented to maintain normal functions in the body including the nervous system. However, folic acid is mostly regarded as non-toxic, the possible consequences of excessive long-term folic acid intake in mammals are controversial $(11,13,16,18,19)$. In accordance to data in humans $(15,18-22)$, studies in laboratory animals (2329) have suggested that folic acid has neurotoxicological effects by unknown mechanisms. It has been confirmed that folic acid and some of its reduced derivatives have certain biological properties in common with the excitatory amino acids $(16,27)$. Folates have been shown to be excitants of neuronal tissue produce degeneration of neurons and produce convulsions when injected directly into the brain $(23-26,28,29)$. Recent studies have suggested that folates may act as neuromodulators or neurotransmitters in the central nervous system. Overall, these studies suggest that folates in brain may function as endogenous excitatory amino acid neurotransmitters or neuromodulators (29). After intracerebral injections of folate compounds, the

Table 2: Organ weights of the groups.

\begin{tabular}{|c|c|c|c|c|c|c|c|c|}
\hline \multirow[b]{2}{*}{ GROLPS } & \multirow{2}{*}{$\begin{array}{c}\text { Absolute } \\
\text { brain weight } \\
\text { (mean } \pm \mathrm{SD}\end{array}$} & \multicolumn{7}{|c|}{ ROWs * (mean $\pm S D)$} \\
\hline & & Heart & Lung & Liver & Kidneys & Spleen & Thymus & Adrenal glands \\
\hline $\begin{array}{c}1 \\
\text { (control) }\end{array}$ & $2.085 \pm 0.07$ & $0.632 \pm 0.07$ & $1.080 \pm 0.68$ & $7.329 \pm 0.687$ & $1.421 \pm 0.184$ & $0.297 \pm 0.036$ & $0.288 \pm 0065$ & $0.025 \pm 0.003$ \\
\hline II & $2.109 \pm 0.09$ & $0.680 \pm 0.07$ & $1.014 \pm 1.19$ & $8118 \pm 1.273$ & $1.681 \pm 0.119$ & $0.312 \pm 0.033$ & $0.246 \pm 0.067$ & $0.032 \pm 0.005$ \\
\hline $16 \mathrm{i}$ & $2.114 \pm 0.08$ & $0.670 \pm 0.09$ & $1.140 \pm 1.44$ & $7.707 \pm 1.341$ & $1574 \pm 0.143$ & $0.317 \pm 0.060$ & $0.243 \pm 0.062$ & $0.033 \pm 0.005$ \\
\hline$F(2,27)$ & 0.378 & 1.103 & 2.155 & 1.202 & 7.429 & 0.530 & 1.476 & 10.165 \\
\hline$p$ & $n \cdot s:$ & n.s. & n.s. & $n . s$. & 0.003 & n.s. & n.s. & 0.001 \\
\hline
\end{tabular}

* ROWs were calculated as: Absolute organ weigth/Absolute brain weigth; $\mathbf{n} . \mathbf{s}=$ not significant

organ weights (ROWs), the absolute weight of organs of an animal was divided by the absolute brain weight of the same animal. Tab. 2 is also shown relative weights of the organs of all groups. Relative weights of kidneys and adrenal glands in both of Group II and III were greater than in the control group $(p<0.05)$. These differences were not dose-dependent $(p>0.05)$. There were no significant differences in the other organs (heart, liver, lung, spleen, thymus; $\mathrm{p}>0.05$ ). neurotoxicity, generally characterized as a decrease in presynaptic enzyme markers, may occur at the site of injection as well as at distal sites $(26,29)$. It is also suggested that the active folate compounds may induce the release of dopamine from nerve terminals in the nucleus accumbens, resulting in activation of postsynaptic dopamine receptors in this region of the brain (29). Likewise, folate overload could potentially result in abnormal methylation of catecholamines or indoleamines resulting in the alterations in monoaminergic neurotransmission (30). Thus folates present in 
brain tissue are distributed in a large concentration in the synaptosomal fraction and are released under conditions which depolarize neurons $(5,29-31)$. In addition, it has been also shown that the optic tract contains a high amount of folate in human brain, but further investigations are still required (30). On the other hand, it is also suggested that the known cofactor functions of folates can not explain their excitant and neurotoxin effects, which are probably related to effects in plasma membranes. Folate effects upon $\mathrm{G}$ proteins could alter signal transduction or the coupling between receptor stimulation and release of second and third messengers. G proteins appear to be substantially more numerous than transmitter receptors, thereby providing a means of signal amplification. Alteration of $\mathrm{G}$ protein function is one means of modulating the effects of hormons and neurotransmitters. Inhibition of GTPase activity by folic acid could potentiate the effect of intercellular signals, due to a longer duration of an activated state. This might cause convulsive seizures if the $G$ proteins influenced by folates were associated with excitatory pathways (16). In the present study, we did not detect any behavioural test result differences in $\mathrm{OF}$ motor activity and in ASR. Additionally, our electrophisiologic data could not confirm others which showed that intraamygdaloid injections of folates, notably itself, reproduce the limbic seizure/brain damage syndrome associated with kainic acid (26). Some findings including seizures were not observed in the study. Most probably these results were originated from different doses, treatment period, and application route to animal. It is an important point that folic acid was applied by gavage in this study while others directly injected folic acid into the brain (23-29). Moreover, this study did not aim to investigate receptor-or biochemically related parameters. The failure of determination of either folate levels or related enzyme activities may contribute to some uncertainty of the data in the study. On the other hand, shorter latency of waves in the visual and the lengthened latency of waves in the somatosensory cortical areas were found and the data suggest that folic acid may alter certain bioclectric functions in the brain. Even though, as there were practically no qualitative differences in the trends of behavioural and/or neurophysiological changes among the groups, it can be concluded that folate derivatives have diverse roles in the brain tissue. In spite of no specific explanation of these observations, these trends seem very important to show useful effects of folic acid in visual areas, and also this situation only may be explained by a potential effect of folic acid on the normal function of the important neurons in the cerebellum.

Folic acid at two-dose levels did not affect body- weight in rats. On the other hand, after evaluation of relative organ weights, we observed some differences between the groups in kidneys, and adrenal glands (statistical significant), and in thymus and spleen (not statistical significant). It is well known that there is close interrelation between central nervous system and immune systems. As a result of this, we conclude that further investigations including basic-immunological parameters are also needed to evaluate effects of folic acid supplementation.

Apparently, folate plays a role in central nervous system. Therefore, any changes in folate pathway may cause some alterations in the system. Possible risks of the dietary supplementation and fortification of folic acid should not be underestimated. We conclude that biochemically-based toxicological investigations are needed to be able to explain the mechanism of folic acid toxicity.

\section{Acknowledgments}

T.B. was granted by the HAS and TUBITAK for this study.

\section{References}

1 Reisenauer AM, Ilalsted $\mathrm{CH}$ : Human folate requirements. J Nutr 117: 600-602, 1987

2 Ubbink JB: Should all elderly people receive folate supplements? Drug Aging 13:415-420, 1998

3 Blakley RL, Benkovic SJ: Folates and pterins. New York: John Wiley\&Sons Inc 1984

4 Picciano MF, Stokstad ELR, Gregory JF: Folic acid metabolism in health and disease. New York: Wiley-Liss Inc 1990

5 Martinasevic MK, Rios GR, Willer MW, Tephly TR: Folate and folate-dependent enzymes associated with rat CNS development. Develop Neurosci 21: 29-35, 1999

6 Achon M, Alonson-Aperte E, Reyes L, Ubeda N, Varela-Moreiras G: High-dose folic acid supplementation in rats: effects on gestation and methionine cycle. Br J Nutr 83: 177-183, 2000

7 Stickel F, Choi SW, Kim YI, Bagley PJ, Seitz HK, Russell RM, Selhub J, Mason JB: Effect of chronic alcohol consumption on total plasma homocysteine level in rats. Alcoholism: Clin Exp Res 24: 259-264, 2000

8 Mason JB, Selhub J: Disease prevention: broadening the definition of folate nutrition. Nutr Clin Care 2: 82-86, 1999

9 Butler IJ, Rothenberg SP: Dietary folate and biogenic amines in the CNS. J Neurchem 49: 268-271, 1987 
10 Long M, Weir D, Scott J: Source of methyl groups in brain and nerve tissue in the rat. J Neurochem 52: $377-380,1989$

11 Young SN: Some effects of dietary components (amino acids, carbohydrate, folic acid) on brain serotonin synthesis, mood and behaviour. Can J Physiol Pharmacol 69: 893-903, 1989

12 Wu D, Pardridge WM: Blood-brain barrier transport of reduced folic acid. Pharm Res 16: 415-419, 1999

13 Butterworth CE, Tamura T:_Folic_acid_safety_and toxicity:_a brief review. Am J Clin Nutr 50: 353 358,1989

14 Hathcock JN. Nutrition Toxicology. New York: Academic Press 1982

15 Campbell RC: How safe are folic acid supplements? Arch Inter Med 156: 1638-1644, 1996

16 Hartley DM, Snodgrass SR: Folate interactions with cerebral G proteins. Neurochem Res 15:681686,1990

17 Dési I: Neurological investigation of pesticides in animal experiments. Neurobehav Toxicol Teratol 5: 503-517, 1983

18 Hunter R, Barnes J, Oakeley HF, Matthews DM: Toxicity of folic acid given in pharmacological doses to healthy volunteers. Lancet 1: 61-63, 1970

19 Hellström L: Lack of toxicity_of folic_acid_given in pharmacological doses_. to healthy_volunteers, Lancet 1: 59-61, 1971

20 Richens A: Toxicity of folic acid. Lancet 1: 912 , 1971

21 Sheehy TW: Folic acid: lack of toxicity. Lancet 1: 37,1973
22 Katz M: Potential danger of self-medication with folic acid. N Engl J Med 289: 1095, 1973

23 Spector RG: Folic acid and convulsions in the rat. Biochem Pharmacol 20: 1730-1732, 1971

24 Hommes OR, Obbens EAMT: The epileptogenic action of Na-folate in the rat. J Neurol Sci 16: 271 281, 1972

25 Baxter MG, Miller AA, Webster RS: Some studies on the convulsant action of folic acid. $\mathrm{Br} \mathrm{J}$ Pharmacol 48: 350-351, 1973

26 Olney JW, Fuller TA, Gubareff T: Kainate-like neurotoxicity of folates. Nature 292: 165-167, 1981

27 Roberts PJ, Hoster GA, Thomas EM: Neurotoxic action of methyltetrahydrofolate in rat cerebellum unrelated to direct activation of kainate receptors. Nature 293: 654-655, 1981

28 Tremblay E, Berger M, Nitecka L, Cavalheiro E, Ben-Ari_Y: Amultidisciplinary_study_of folic_acid neurotoxicity: Interactions_with_kainate_hinding sites_and relevance_to_the_aetiology_of epilepsy. Neurosci 12: 569-589, 1984

29 Stephens RL, Uretsky NJ: Folate induced-hypermotility response after bilateral injection into the nucleus accumbens of the rat. Neuropharmacol 25: 887-896, 1986

30 Yoshino Y, Koike H, Wakabayashi Y, Sawaguchi Y: Regional distribution of folate_in human brain. J Neurochem 33: 977-979, 1979

31 McClain LD, Carl GF, Bridgers WF: Distribution of folic acid coenzymes and folate dependent enzymes in mouse brain. J Neurochem 234: 719 722,1975 